\section{A RETROSPECTIVE ON IVAN ILLICH}

We devote a considerable amount of space to Ivan Illich, who died in December 2002. This includes his original article "Medical Nemesis", which was published in the Lancet in 1974, and his obituary from the London Times from last December, republished by kind permission of the newspaper. We also have several personal perspectives on a man who would have been regarded in Yorkshire as somewhat "rum". These pieces speak for themselves, but clearly Illich was unique and in his writings he challenged the hegemony of medicine (as well as other professional groups) possibly more effectively than the British playwright George Bernard Shaw, who described all professions as being "conspiracies against the laity". ${ }^{1}$ As Richard Edwards points out, Illich anticipated the evidence based healthcare movement, and he was anticipating the need for an economics of health rather than the economics of health care, which is what we have at the moment. It will come as a revelation to many readers that the nearest $B M J$ editor, Richard Smith has ever come to a religious experience was listening to Ivan Illich as a medical student, and that this caused him to drop out of medical school for three days. Finally, editorial board member Lowell Levin throws some light on Illich the man with his essentially human contradictions and his penchant for fine wines and food (among other things).

See pages 919, 923, 925-8

SARS continues to make it to our pages, and will probably do so for a long time to some. We have photographs from a school in Hong Kong that show how participation in Healthy Cities and Healthy Schools initiatives can play their part in responding to a major public health threat, something which is further explored in a paper by Albert Lee and his group.

\section{See pages 945,950}

JECH Gallery this month also features American occupational health pioneer Harriet Hardy, who made extensive contributions to the progress of this discipline; and Speaker's Corner gives vent to the communication gap between scientists and decision makers. More Speaker's Corner contributions would be welcome.

\section{See pages 924, 918}

From England, where public health networks are increasingly seen as the vehicle for delivering health improvement, comes an early analysis of the issues raised by this non-traditional organisational form; while other Evidence Based Public Health Policy and Practice contributions include:

- Question: how willing are parents to improve pedestrian safety in their community? Answer: moderately (median willingness to pay for speed bumps $\$ 6.43)$.

- Question: can risk assessment be applied to prioritising land mine clearance? Answer: yes_-this from Chad and Thailand.

- Question: can self ratings of health predict outcome after stroke? Answer: with caution.

\section{See pages 938, 951, 956, 960}

The section on Continuing Professional Education includes an interesting and wide ranging interdisciplinary Glossary on economics, demography, and epidemiology; and in an insightful piece of self inspection we ask why are women underused in the JECH peer review process?

\section{See pages 929,936}

Research findings include:

- The one child family rule seems to be an important cause of the high sex ratio at birth observed in China in the past 20 years.

- Maternal short stature, low social class, and smoking during pregnancy influence the development of "high risk" for adult chronic disease.

- There is socio-cultural advantage to living in high density Mexican-American neighbourhoods when it comes to risk of depression.

\section{See pages $967,969,987$}

A book review to note this month is the comprehensive and very important World Health Organisation report on violence and health; and an important finding reported in our Letters page from the USA is that for every divorced woman that commits suicide, over nine divorced men kill themselves-dramatising the terrible consequences of being a divorced man in America.

See pages 993, 994

From Hygieia, three important findings:

- From MMR research, that since the furore this research is now complicated by recall bias in parents.

- Negativity follows inactivity—healthy eating and regular exercise are important for energy levels.

- There has been a marked increase in hate related violent crime against people perceived to be from the Middle East in New York City and Washington DC since 11 September 2001.

\section{See page 996}

\section{REFERENCE}

1 Ashton JR. "All professions are conspiracies against the laity" (George Bernard Shaw). J Epidemiol Community Health 2003;57:161. 